\title{
Wait, But Why? \\ Challenging \\ the Intuitive Force \\ of Substance Dualism
}

\section{SARAH LANE RITCHIE}

University of Edinburgh

sarahlaneritchie@gmail.com

ORCID: 0000-0003-4487-5725

\begin{abstract}
In responding to Joshua Farris' The Soul of Theological Anthropology, I suggest several reasons for questioning the theological need for substance dualism in any form. Specifically, I argue that it is not at the level of analytic argumentation that the mind or soul is best understood, and that the sciences do indeed challenge substance dualism (despite philosophical arguments to the contrary). In making this argument, I examine the roles of intuition and theological pre-commitments in one's determination of the correct understanding of the mind or soul. I suggest that dualism is not only theologically unnecessary, but also an intuition that we have reason to question.
\end{abstract}

Keywords: physicalism; intuition; mind; soul; body; dualism.

\section{Introduction}

In offering a response to Joshua Farris' The Soul of Theological Anthropology, it is perhaps useful to clearly state this response's underlying assumptions and aims. Namely, I do not intend to argue against the finer points of Farris' 
argument, but rather to question the intuitions and presuppositions on which the argument is based. Indirectly, then, this means that it is only fair to acknowledge that the current response does not engage The Soul of Theological Anthropology in the manner which the author would have likely intended. Farris' book offers a sustained argument for a very specific, detailed form of substance dualism, but does not purport to address interlocuters whose intuitions and theological frameworks do not commit them to any form of dualism whatsoever. To not acknowledge this would be disingenuous and unhelpful; it is all too common for academics to purportedly debate a topic using the same words and concepts, all the while missing an opportunity to name, own, and discuss the real commitments and dispositions underlying the more obvious technical disagreements. In what follows, then, I will not engage Farris' sophisticated and intricate argument on the merits of its finer points. Rather, the intention is to name and question the role and persuasive thrust of intuition in one's understanding of mind (particularly given scientific insights on the role of intuition and the seemingly self-evident), to hint at the theological pre-commitments that feed into the felt need for substance dualism in the first place, and to suggest (contra many a dualist!) that consciousness does, indeed, fall within the explanatory purview of empirical scientific inquiry.

\section{I.}

At this point, it is right to point out that it is the strength and clarity of Farris' book that allow one to locate real sources of disagreement. In debates about the mind-body relationship - and particularly in the field of science and theology - there is an awful lot of 'bet hedging' that occurs. Let us suppose that on one end of the spectrum we have Farris' specific version of Cartesian substance dualism, what he calls person-body substance dualism (PBSD). Nearer the other end of the contemporary mind-body spectrum, we have some form of anti-reductionist physicalism, broadly defined. In order to avoid the negative connotations associated with physicalism, let us call this position 'integrated physicality,' and characterise it by the admittedly 
broad affirmation that the human mind or soul just is what it is to be the unimaginably complex system of systems that involves a functioning brain in a sufficiently healthy human body, situated within an immensely complex physical, social, and linguistic environment. (Note that I intentionally avoid advocating any specific and particular position on the ontology of consciousness. Doing so would distract from the main thrust of this response, which, as stated, seeks to address intuition and pre-commitments, rather than the fine-grained detail of either Farris' argument or my own.) To be a human body, with all the physical, psychological, cultural, and linguistic aspects that are inherently involved in the formation of that organism, is constitutive of personhood.

If these two positions are relatively near the respective ends of the theological anthropological spectrum, then most theologians exist somewhere in the middle. There is a strong, perhaps begrudging, awareness that at the very least, the human body (particularly the brain) is in some way related to the mind or soul. Even staunch substance dualists such as Richard Swinburne would agree that "fairly obviously most conscious events are caused by brain events which are often themselves caused by physical events in or around the person's body" (Swinburne 2013, 100). And yet, there is an even stronger intuition and conviction that the human body cannot be the whole story of mind, soul, or personhood. Or to put it even more strongly, "There is considerable diversity in how we think about the soul and its destiny, but that we have souls, spiritual or non-material parts of us that are distinct from our bodies and capable of surviving the death of our bodies, is a perennial and widespread human conviction" (Crisp, Porter, and Ten Elshof 2016, 1). The result of these duelling intuitions and observations is a myriad of positions such as Philip Clayton's strong emergence (Clayton 2004), Nancey Murphy's nonreductive physicalism (Murphy and Brown 2007), and even William Hasker's emergent dualism (Hasker 2018), positions which all seek to have the proverbial cake and eat it too: "My body is very important for my existence, in some way, but we must always insist upon that mysterious 'something more' that is inexplicable in scientific terms and transcends physical mechanisms." Some such positions fall under the umbrella of 
'property dualism,' while Oliver Crisp labels some positions stemming from this motivation as "refined substance dualisms": views that "try to make the case that traditional ways of thinking about humans that are substance dualist in nature need some significant revision in light of contemporary work in neuroscience and philosophy of mind" (Farris 2017, xiv).

Because of this ubiquitous tendency to equivocate, some may find it refreshing to encounter a book such as Farris' in which the author so clearly takes a position that lies just outside the circle of mainstream theological discussion. It is dishearteningly rare to find a scholar with the dispositional inclination to say: "No, do not attempt to soften my position into one of those dualism-lite alternatives. I really mean to say that I am a substance dualist, and persons are strictly identical to immaterial souls. I know this position cuts against the mainstream of academic theology, but so be it, for it is the position that most closely aligns with Scripture, Christian tradition, and lived experience, and it is also philosophically defensible." Thus, one might appreciate Farris' work for its stark and uncompromising exposition of Cartesian substance dualism.

Of course, Farris' book is notable for more than the author's willingness to take a stand on a somewhat unpopular position. His treatment of substance dualism is handled with an impressive level of rigor, and Farris exemplifies the best that the methods of analytic theology have to offer: precision, clarity, and a high degree of nuance in the explication of definitions, assumptions, and implications of the many varieties of substance dualism. Farris is not content to discuss a generic version of substance dualism, but spends a good portion of the book carefully drawing distinctions between difference forms of dualism, comparing their respective advantages and disadvantages for a biblically-informed Christian theology, and only then spelling out the intricate details of his own 'emergent creationism.' If William Abraham is correct that analytic theology is "the articulation of the central themes of Christian teaching illuminated by the best insights of analytic philosophy," then surely Farris' defence of substance dualism is an exemplary application of this method as applied toward theological ends (Crisp and Rea 2009, 54). 
Of particular value is Farris' recognition that there is something about human embodiment that is important. In his emergent creationism, 'souls are created by God but souls only come into existence in conjunction with their bodies in time as emergent souls or as a distinct emergent nature; where bodies, having their own properties/powers, become causally necessary for souls and vice versa'(Farris 2017, 76). Hence this is a version of substance dualism that recognizes the importance of physical bodies, insisting that a human soul - a human person - is not created until there is a physical body able to receive that soul: the soul "has an integrated and holistic relationship to the body and the kind-nature of the soul is explanatorily made sense of in terms of the soul's coming into existence via its structural relationship to the body" (Farris 2017, 76). While bearing strong resemblance to Hasker's emergent dualism, then, emergent creationism interestingly both affirms the direct creation of the soul by God (contra Hasker), while still affirming that the body is important for one's anthropology. The explication of this position is handled well, and if one is committed to preserving a strong substance dualism using the tools of analytic theology, Farris' argument may well be the one to beat.

\section{II.}

However, this brings me to the inescapable question: "Wait, but why?" Given that so many Christian theologians (eg., Philip Clayton [2004], Veli-Matti Kärkkäinen [2016]), philosophers (eg., Kevin Corcoran [2006], Peter van Inwagen [1995]), Nancey Murphy [Murphy and Brown 2007]), and biblical scholars (eg., Joel Green [2015], Mark Harris [2014], NT Wright [2013]) have considered substance dualism to be theologically unnecessary, why would one insist upon a position that seems at odds with much of contemporary science (notwithstanding the usual objections that the mind or soul is not the sort of thing that could ever be addressed by the sciences in the first place)? Is substance dualism in any form really a theological necessity? And perhaps more importantly, why are Christian theologians so divided on their intuitive responses to that question? Of course, theological anthropology 
has been well-handled by all manner of interested parties, and it is not my intention to rehearse detailed arguments against dualism from Biblical studies, systematic theology, philosophy, cognitive science of religion, or the various brain sciences. What is worth reiterating (and this is nothing new) is that one's background commitments make all the difference when addressing the question of mind, soul, and body: commitments involving hermeneutical lenses and Scriptural interpretation, implicit metaphysical models of the God-creation relationship, relationship between physical matter and God, etc. In addition to such conscious and explicit background commitments is the more subtle (but perhaps more powerful) role of intuition: that visceral sense of what is or can be true, and which plays a not-insignificant role in adjudicating which explanations (philosophically, theologically, and even scientifically) we deem to be persuasive. Peter van Inwagen describes this nicely, writing that intuitions may be, "in some cases, the tendencies that make certain beliefs attractive to us, that 'move' us in the direction of accepting certain propositions without taking us all the way to acceptance” (van Inwagen 1997, 309). As persuasive as Farris' PBSD might be, given certain commitments and intuitions, I suggest that it is precisely at the level of pre-commitments and intuitions that the real work needs to be done when it comes to questions of the mind or soul.

What remains, then, is to highlight the role of the background commitments predetermining which approaches to the mind or soul we are willing to take seriously, and to encourage suspicion of our collective intuition when it comes to the ontology of mind. Indeed, it is fairly clear that the real departure point between various readers occurs quite early in Farris' book, where he writes: "Attending to my mental states, it becomes plain that I as a thing with mental states am just different from my body....strictly speaking I am not my body...I am distinct from my body, which seems to be basic upon reflection...I readily make an intuitive assumption that I am not identical to my body...I intuitively believe that I am not body" (Farris 2017, 19). In many ways, it is from this basic, felt sense of intuitive dualism that Farris' entire argument proceeds. It is the motivation and foundation for everything that comes next, and as such, the argument for person-body substance dualism 
is only as sound as one's intuition in regards to the immateriality of mind. Given, then, that the natural sciences have proved remarkably effective at explaining so many of the cognitive and perceptual functions previously associated with an immaterial mind, and have also provided reasons to question the epistemological validity of brute intuition, it is thus at the level of pre-commitments and intuition that the real conversation needs to take place - rather than a sustained debate about the finer analytical points supporting the pre-determined conclusion that substance dualism is theologically necessary.

Here it is useful to make a few brief remarks about theological pre-commitments, and then set those aside in order to turn to intuition and the question of whether the mind is or is not a proper object of scientific inquiry. Oliver Crisp has written that analytic theology involves both procedural and substantive elements. On the procedural side, analytic theology is characterised by the methods and style of contemporary analytic philosophy; there are "certain assumptions about why this procedure and not some other currently on offer is better suited to the task of theologizing" (Crisp 2009, 35). On the substantive side, analytic theology is marked by "several features that are interrelated: the presumption that there is some theological truth of the matter and that this truth of the matter can be ascertained and understood by human beings (theologians included!), and an instrumental use of reason" (Crisp 2009, 35). What seems clear on a birds-eye view is that Farris' PBSD is essentially a robust and persuasive analytic argument that deploys the "tools" of analytic philosophy in support of a pre-existing conviction that substance dualism is theologically necessary. It is not, I suggest, an exploration into whether or not substance dualism is actually theologically necessary. To be clear: the intention here is not to critique analytic theology as a whole. Rather, it is important to determine the right theological tools for the job at hand, and to be clear about the extent to which we are willing for those tools to lead us to surprising or unexpected conclusions (Perry and Ritchie 2018). I wholeheartedly agree that an "instrumental use of reason" is vital in discussions of the mind. The suggestion here is simply that 1) the argument at hand neglects many of the "right tools" (eg the sciences), and 
2) that the correct use of reason must in this case engage with empirical inquiries into physical and psychological processes, including those that cast suspicion on the epistemological weight often attached to intuition. Indeed, these points have led a great many Christian scholars to reject substance dualism (as noted and cited above), arguably leading to even more robust theological, philosophical, and biblical scholarship. Farris' PBSD is a very strong analytic argument, but the conclusion it is intended to support may well be indefensible when other tools and commitments are seriously entertained.

\section{III.}

Leaving theological method and pre-commitments aside, we turn now to the complex question of intuition. It is highly significant that it is possible not only to question the reliability of one's intuition that the mind is ultimately distinct from physical processes, but also to legitimise the question of consciousness as a proper scientific problem. Here a word about terminology becomes important. I follow Farris and most others in this discussion by using the words mind, consciousness, and soul interchangeably. Note, however, that this conflation of mind and soul has a very interesting history worth looking into, and that this conflation has put dualists on ever-shakier ground as the various brain sciences have made significant inroads into the study of mental experience and functioning (Malik 2001, 37). It has not always been the case that 'soul' has been equated with 'consciousness' as defined by philosophers of mind. For example, Thomistic hylomorphism would see what we call the 'mind' as being but one part of the soul/body whole, and would likely not equate soul with 'subjective conscious experience' in quite the same way as substance dualists (Adams 2016). Observers of dualistic arguments might well find it puzzling that even the most prominent advocates substance dualism so willingly conflate soul with mind.

Of course, what most dualists mean by the soul or immaterial mind is just that seemingly nonphysical phenomenon of first-person, subjective experience. There is just something it is like to be me, and this "something" 
seems intuitively and obviously distinct from whatever neurobiological descriptions might be used to describe my neural activity (Nagel 1974). David Chalmers" classic "hard problem of consciousness" captures the spirit of this intuitive dualism well: "An organism is conscious if there is something it is like to be that organism," and we have no good reason to think that scientific descriptions of neural processes could ever render a satisfactory explanation for this reality (Chalmers 1997, 11). Or as Philip Clayton puts it, subjective conscious experience "does not seem to be the kind of thing that could be explained in terms of functions or structures" (Clayton 2006, 133). Chalmers, of course, divides consciousness into this hard problem of subjective experience on one hand, and the so-called "easy problems" of consciousness on the other: attention, behaviour control, access to mental states, reportability, information integration, and the ability to react to the environment (Chalmers 1997, 9). Many dualists are happy to acknowledge that the brain sciences can fully explain these functional capacities, but will still insist that intuition - presumably assumed to be a universal or near-universal intuition - commits them to the affirmation that "to account for conscious experience, we need an extra ingredient in the explanation" (Chalmers 1997, 17). But do we?

Of course, there is the well-rehearsed critique that the mind-body "problem" is almost always framed in a philosophically-flawed question-begging manner in which the mind is presupposed from the outset to be distinct from the body. Arguments against a physicalist understanding of consciousness almost always presuppose the very thing that the physicalist would object to: the immaterial, perhaps super- or supra-natural nature of subjective experience. As Patricia Churchland argues, "the trouble with the 'Hard Problem' characterization is that on the strength of a proprietary definition, it rejects [potential scientific explanations] as wrong" (Churchland 1997, 38-39). Dualists generally define consciousness as "subjective experience which is necessarily immune to scientific analysis," thereby defining the problem in a proprietary manner that constrains the conversation from the outset. Leaving this aside, though, it is certainly apparent that debates about mind almost always come down to what Chalmers himself has called 
a "brute clash of intuitions...Explicit argument can help us to isolate and characterize the clash, but not to resolve it" (Chalmers 1996, 167). For many, mind intuitively seems qualitatively different from atoms and molecules, leading them to appeal to what Richard Swinburne calls "the apparent obviousness of 'matter cannot produce thought;'” philosophical arguments are thus constructed using the nonphysicality of the mind as a sort of brute fact, a starting point in one's theological anthropology (Swinburne 2004, 193).

But what happens when the "Hard Problem" does not seem all that hard? Indeed, many in philosophy of mind and the various brain sciences flatly reject the way the mind-body problem is framed, and the intuitive foundation on which it is based (Dennett 2015). As Patricia Churchland argues, "Whether we can or cannot imagine a phenomenon being explained in a certain way is a psychological fact about us, not an objective fact about the nature of the phenomenon itself" (Churchland 1997, 42). My inability to imagine a satisfying physical explanation of what we are calling the mind or soul is simply not a good indication of reality. The history of science is riddled with examples of seemingly mysterious or supernatural phenomena being progressively explicated in scientific terms; or as Charles Coulson once quipped, "There is no 'God of the gaps' to take over at those strategic places where science fails; and the reason is that gaps of this sort have the unpreventable habit of shrinking" (Coulson 1955, 20). Moreover, it is worth noting that even the most hard-core physicalists do not expect their explanations to feel intuitively satisfying for those whose dualism is grounded in the apparently self-evident distinction between body and mind. As Valerie Gray Hardcastle writes, "scientific theories of consciousness won't explain the weirdness of consciousness to those who find the identify [of the mind and brain] weird" (Hardcastle 1997, 63). Indeed, given our first-person perspective, complete lack of objective distance from the subject matter under discussion, and the limited abilities of the particular brains that we have, why should we even expect a scientific explanation of consciousness to overcome our intuitive dualism (McGinn 1989)?

The problematic role of intuition in philosophical thinking has long been acknowledged.: as Alfred Ayer wrote, "unless it is possible to provide 
some criterion by which one may decide between conflicting intuitions, a mere appeal to intuition is worthless as a test of aproposition's validity" (Ayer 1936, 106). Moreover, the appropriate role of intuition in cognition more broadly is hotly contested (Kiel 2010, Shtulman and Schulz 2008). The trustworthiness of intuition is by no means established as certain within any discipline or on any task: the sheer volume and breadth of the research on cognitive biases should give us pause before placing too much weight on any thought or belief that seems self-evidently true. Indeed, "where biases exists, individuals draw inferences or adopt beliefs where the evidence for doing so in a logically sound manner is either insufficient or absent" (Haselton, Nettle, \& Andrews 2015, 725). This is not to say that intuition is not valuable (it is), and there is certainly a great deal of research left to be done on how intuition has evolved and how it functions in different phenomenological experiences and intentional cognitive tasks. But to rely on intuition is anything but a safe bet in philosophy and theology, particularly when (as in the case of the mind) there is actually a great deal of scientific reason to question a particular intuition. The challenge to intuitive dualism becomes even starker when we realize that there exist "theories of error" about why we would mistakenly form intuitive beliefs about dualism in the first place. That is, cognitive science, evolutionary psychology, and the brain sciences more broadly can produce explanatory models that describe how and why we naturally form erroneous intuitions about the self (Schwitzgebel and Gordon 2000, Gilovich, Griffin, and Kahneman 2002).

If, for the moment, we can lay aside intuition, the question then arises: Why would we feel the need to posit extra bits of metaphysical furniture in our theological anthropology, when every indication from the sciences suggests the through-and-through physicality of all those specific functions and features of the human mind that, in sum, seem not to require that "extra ingredient” of an immaterial soul? Does Christian theology require substance dualism? I and many others have written elsewhere about the richly textured metaphysical picture that various Christian traditions have to offer to this conversation, broadly challenging the assumption that physicality necessarily stands in ontological contrast to the spiritual. I will 
thus not rehearse those arguments here, but merely suggest that there are indeed "theological frameworks that remove the need for defensiveness or theological anxiety in the face of scientific, physicalist explanations of the mind...Not only is the mind not nonphysical but also theologically speaking it does not need to be more than physical" (Ritchie 2019, 350). This is because "physicality does not stand in dichotomous relationship to God. A complex physical picture of the mind need pose no threat to dynamic interaction with God - if indeed it is true that 'in him we live and move and have our being'" (Ritchie 2019, 350). In other words, if one's understanding of the God-nature relationship is such that physicality itself is recognised as being always and already involved with God, then carving out the mind as immaterial seems far less necessary.

Space would not permit a full discussion of the great many theologians, biblical scholars, and Christian philosophers who have identified textual, theological, and philosophical reasons to challenge dualism and adopt one or another monistic approach to the human person. As just one example, note that many biblical scholars would agree with Joel Green that "an anthropology that that posits an ontologically distinct soul...is not only unnecessary but actually stands in tension with key aspects of the resurrection message of the Scriptures" (Green 2004, 86). Perhaps here it is most constructive simply to point out that alternatives to dualism - even physicalism - need not be caricatured in the flatly reductionist way in which dualists usually portray them. To the extent that dualism is driven by fears that the human person will be explained away as being "nothing but a pack of neurons," the breadth and nuance of non-dualistic positions should be recognised (Crick 1994, 3). One can affirm a sort of expansive physicalism and agree with Willem Drees that reductionism is inappropriate: "the description and explanation of phenomena may require concepts which do not belong to the vocabulary of fundamental physics, especially if such phenomena involve complex arrangements of constituent particles or extensive interactions with a specific environment" (Drees 1996, 12). Recognising human physicality need not be seen as a materialist attempt at removing God from the causal and explanatory picture of reality. 


\section{Conclusion}

Thin descriptions of physicalism are just as unhelpful as the confused and caricatured portrayals of substance dualism that Farris so ably surpasses. Indeed, the emerging physical picture of the human being is one that is quite literally - unimaginably complex, a picture including not just brain tissue, but systems of systems involving increasingly intricate biological processes, which themselves produce emergent features which cannot be described in reductionistic fashion. Moreover, it is becoming increasingly clear that the comfortable old categorical boxes we use in our ontological descriptions are problematic; it is inappropriate to try to cram the fuzzy, messy realities of biological systems into neatly defined and strictly boundaried ontological categories such as 'soul and body' or 'mental substance and physical substance.' Our mental lives are not only embodied, but involve processes and interactions outside the brain itself (Varela, Thompson, and Rosch 1991, Clark and Chalmers 1998). An honest physicalism will never be a flatly reductionistic description of neural activity, but will always paint the most nuanced, dynamic, and richly coloured picture of the human person that is, I would suggest, even more theologically rich than that offered by substance dualism. By challenging intuition, non-defensively engaging with the wildly successful research projects produced by the various brain-related disciplines, and exploring theological models in which God is always involved with the physical world itself, substance dualism becomes not only theologically unnecessary - but incapable of doing justice to the full range of resources offered by Christian theology and history.

\section{References}

Abraham, William J. 2009. “Systematic Theology as Analytic Theology.” In Analytic Theology: New Essays in the Philosophy of Theology, edited by Oliver Crisp and Michael C. Rea, 54-66. Oxford: Oxford University Press.

Adams, Marilyn McCord. 2016. "What about Hylomorphism? Some Medieval and Recent Ruminations on Swinburne's Dualism.” In Reason and Faith: Themes from Richard Swinburne, edited by Michael Bergmann and Jeffrey E. Brower, 220-243. Oxford: Oxford University Press. 
Ayer, Alfred J. 1936. Language, Truth, and Logic. London: Gollancz Ltd.

Chalmers, David. 1996. The Conscious Mind: In Search of a Fundamental Theory. Philosophy of Mind Series. Oxford: Oxford University Press.

Churchland, Patricia. 1997. “The Hornswaggle Problem.” In Explaining Consciousness: The 'Hard Problem, edited by Jonathan Shear, 37-44. Cambridge, MA: MIT Press. Clark, Andy and David Chalmers. 1998. “The Extended Mind.” Analysis 58 (1): 7-19. Clayton, Philip D. 2004. Mind and Emergence: From Quantum to Consciousness. Oxford: Oxford University Press.

Corcoran, Kevin. 2006. Rethinking human nature: A Christian Materialist Alternative to the Soul. Grand Rapids, MI: Baker Academic.

Coulson, Charles Alfred. 1955. Science and Christian Belief. Oxford: Oxford University Press.

Crick, Francis. The Astonishing Hypothesis: The Scientific Search for the Soul. New York: Simon \& Schuster.

Crisp, Oliver D. 2017. Forward to The Soul of Theological Anthropology: A Cartesian Exploration, edited by Joshua R. Farris, xiii-xiv. New York: Routledge.

Crisp, Thomas M., Steven L. Porter, and Gregg A. Ten Elshof. 2016. Neuroscience and the Soul: The Human Person in Philosophy, Science, and Theology. Grand Rapids, MI: Eerdmans.

Dennett, Daniel. 2015. Elbow Room: The Varieties of Free Will Worth Wanting. Cambridge, MA: MIT Press.

Drees, Willem B. 1996. Religion, Science, and Naturalism. Cambridge: Cambridge University Press.

Farris, Joshua R. 2017. The Soul of Theological Anthropology: A Cartesian Exploration. Grand Rapids, MI: Eerdmans.

Gilovich, Thomas, Griffin Dale, and Daniel Kahneman. 2002. Heuristics and Biases: The Psychology of Intuitive Judgment. Cambridge: Cambridge University Press.

Green, Joel B. 2004. "Resurrection of the Body: New Testament Voices Concerning Personal Continuity and the Afterlife." In What About the Soul? Neuroscience and Christian Anthropology, edited by Joel B. Green, 85-100. Nashville: Abingdon Press.

Green, Joel B. 2015. "Why the Imago Dei Should Not Be Identified with the Soul.” In The Ashgate Research Companion to Theological Anthropology, edited by Joshua Ryan Farris and Charles Taliaferro, 179-190. Burlington, VT: Ashgate Publishing. Hardcastle, Valerie Gray. 1997. "The Why of Consciousness: A Non-Issue for Materialists." In Explaining Consciousness: The 'Hard Problem, edited by Jonathan Shear, 61-68. Cambridge, MA: MIT Press.

Harris, Mark. 2014. “Does Jesus Have a Soul? The Apollinarian Controversy Revisited.” In The Concept of the Soul: Scientific and Religious Perspectives, edited by Michael Fuller, 75-81. Cambridge: Cambridge Scholars Publishing. 
Haselton, Martie G., Daniel Nettle, \& Paul W. Andrews. 2015. “The Evolution of Cognitive Bias.” In The Handbook of Evolutionary Psychology, edited by David M. Buss, 724-746. Hoboken, NJ: Wiley and Sons.

Hasker, William. 2018. “The Case for Emergent Dualism.” In The Blackwell Companion to Substance Dualism, edited by Jonathan J. Loose, Angus J. L. Menuge, and James PorterMoreland, 61-72. Oxford: Wiley-Blackwell.

Kärkkäinen, Veli-Matti. "Multidimensional Monism”: A Constructive Theological Proposal for the Nature of Human Nature." In Neuroscience and the Soul: The Human Person in Philosophy, Science, and Theology, edited by Thomas M. Crisp, Steven L. Porter, and Gregg A. Ten Elshof, 201-227. Grand Rapids, MI: Eerdmans. Keil, Frank C. 2010. The Feasibility of Folk Science. Cognitive science 34(5), 826-862. doi:10.1111/j.1551-6709.2010.01108.x

Malik, Kenan. 2001. Man, Beast, and Zombie: What Science Can and Cannot Tell Us About Human Nature. London: Phoenix.

McGinn, Colin. 1989. “Can We Solve the Mind-Body Problem.” Mind. 98:349-366. Murphy, Nancey \& Warren Brown. 2007. Did My Neurons Make Me Do It?: Philosophical and Neurobiological Perspectives on Moral Responsibility and Free Will. Oxford: Oxford University Press.

Nagel, Thomas. 1974. "What is it like to be a bat?" Philosophical Review 83:435-50. Perry, John \& Sarah Lane Ritchie. 2018. "Magnets, magic, and other anomalies: In Defense of Methodological Naturalism.” Zygon 53: 1064-1093.

Ritchie, Sarah Lane. 2019. Divine Action and the Human Mind. Cambridge: Cambridge University Press.

Schwitzgebel, Eric and Michael S. Gordon. 2000. "How Well Do We Know Our Own Conscious Experience? The Case of Human Echolocation.” Philosophical Topics 28: 235-46.

Shtulman, Andrew, and Laura Schulz. 2008. “The Relation Between Essentialist Beliefs and Evolutionary Reasoning.” Cognitive Science 32:1049-1062.

Swinburne, Richard. 2004. The Existence of God. Oxford: Oxford University Press.

Swinburne, Richard. 2013. Mind, Brain, and Free Will. Oxford: Oxford University Press. van Inwagen, Peter. 1995. “Dualism and Materialism: Athens and Jerusalem?” Faith and Philosophy 12:475-488.

van Inwagen, Peter. 1997. "Materialism and the Psychological-Continuity Account of Personal Identity.” Philosophical Perspectives 11:305-319.

Varela, Francisco J., Evan Thompson, and Eleanor Rosch. 1991. The Embodied Mind: Cognitive Science and Human Experience. Cambridge, Mass: MIT Press.

Wright, Nicholas Thomas. 2013. Pauline Perspectives: Essays on Paul, 1978-2013. Minneapolis, MN: Fortress Press. 